\title{
PREOPERATIVE AUTOLOGOUS DONATION OF BLOOD FOR A SIMPLE CARDIAC ANOMALY: ANALYSIS OF CHILDREN WEIGHING UNDER TWENTY KILOGRAMS
}

Hiroshi Masuda, MD

Yukinori Moriyama, MD

Kouichi Hisatomi, MD

Riichiro Toda, MD

Shinji Shimokawa, MD

Yoshifumi Iguro, MD

Shun-ichi Watanabe, MD

Hitoshi Matsumoto, MD

Akira Taira, MD
Objective: Preoperative autologous donation of blood has been expanded to cardiac operations in children. However, because of problems such as lack of cooperation and hemodilution during cardiopulmonary bypass, its efficacy in small children is unclear. This study clarifies the clinical significance of preoperative autologous donation of blood in small children.

Methods: Thirty-seven patients weighing under $20 \mathrm{~kg}$ (age range, 3-9 years; weight range, $13-20 \mathrm{~kg}$ ) underwent preoperative autologous donation and cardiac operations to treat a simple anomaly. Twenty-five age- and weightmatched patients who were not cooperative or refused preoperative autologous donation served as control subjects. Autologous blood was collected by the simple or leapfrog method and stored as blood components. Each collecting volume was 5 to $10 \mathrm{~mL} / \mathrm{kg}$.

Results: The donation was performed $6 \pm 2$ times during $50 \pm 16$ days, and the whole storage volume was $48 \pm 17 \mathrm{~mL} / \mathrm{kg}$. There was no serious complication. The minimum hematocrit level negatively correlated with the priming volume of cardiopulmonary bypass (preoperative donation patients: $P<.01, r^{2}=0.4$; control subjects: $P=.5, r^{2}=0.03$ ). Blood loss did not significantly differ between preoperative donation patients and control subjects, and the transfused blood volumes were $43 \pm 13 \mathrm{~mL} / \mathrm{kg}$ and $29 \pm 22 \mathrm{~mL} / \mathrm{kg}$, respectively. All of the autologous blood products but fresh frozen plasma were reinfused. Use of homologous blood was significantly less in preoperative donation patients than in control subjects $(0 \%$ vs $80 \%, P<.01)$. In preoperative donation patients postoperative recovery in hemoglobin level was significantly better, which is concurrent with a higher reticulocyte level.

Conclusion: Preoperative autologous donation can be performed safely with clinical efficacy, even in children under $20 \mathrm{~kg}$. This can be improved further through coupling with another procedure. (J Thorac Cardiovasc Surg 2000;120:783-9)
$B^{\prime}$ lood conservation has become an essential concept in cardiac operations because it can prevent serious complications caused by homologous blood transfu-

From The Second Department of Surgery, Kagoshima University Faculty of Medicine, Kagoshima, Japan.

Received for publication Dec 30, 1999; revisions requested Feb 18, 2000; revisions received March 31, 2000; accepted for publication May 29, 2000.

Address for reprints: Hiroshi Masuda, MD, The Second Department of Surgery, Kagoshima University Faculty of Medicine, 8-35-1 Sakuragaoka, Kagoshima 890-8520 Japan (E-mail: masuda@med6.kufm.kagoshima-u.ac.jp).

Copyright (C) 2000 by The American Association for Thoracic Surgery

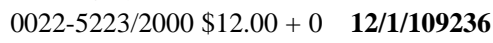

doi:10.1067/mtc.2000.109236 sion, including acute and delayed immunologic reactions, transfusion-associated graft-versus-host disease, viral hepatitis, and retrovirus transmission. ${ }^{1-11}$ This concept may be especially beneficial to children. ${ }^{10,11}$ Preoperative autologous donation (PAD) of blood is an effective method of blood conservation in cardiac surgery that has been applied to patients as young as 4 years of age. ${ }^{5-11}$ In cooperative children weighing at least $30 \mathrm{~kg}$, PAD can be performed as easily as in adult patients. However, PAD in younger or smaller children entails several problems, including noncompliance during blood collection, relatively small blood volume, and remarkable hemodilution during cardiopulmonary bypass (CPB). ${ }^{10-15}$ The present study clarifies the clinical significance of PAD for a simple cardiac anomaly in 
Table I. Preoperative patient profiles

\begin{tabular}{|c|c|c|c|}
\hline Variables & PAD patients $(n=37)$ & Control subjects $(n=25)$ & $\mathrm{P}$ value \\
\hline Age (y) & $6 \pm 1$ & $6 \pm 2$ & .9 \\
\hline Weight (kg) & $19 \pm 2$ & $18 \pm 2$ & .5 \\
\hline $\operatorname{Sex}(M / F)$ & $23 / 14$ & $14 / 11$ & 6 \\
\hline \multicolumn{4}{|l|}{ Diagnosis } \\
\hline $\operatorname{ASD}(\%)$ & $22(60)$ & $15(60)$ & \\
\hline $\operatorname{VSD}(\%)$ & $12(32)$ & $10(40)$ & .7 \\
\hline Others & $3(8)$ & $0(0)$ & \\
\hline \multicolumn{4}{|l|}{ Pre-PAD levels ${ }^{*}$} \\
\hline Hemoglobin (g/dL) & $12.7 \pm 0.8$ & $13.0 \pm 0.9$ & .12 \\
\hline Reticulocytes $(0 / 00)$ & $10 \pm 4$ & $10 \pm 6$ & .2 \\
\hline Platelets $\left(10^{3} / \mu \mathrm{L}\right)$ & $278 \pm 64$ & $280 \pm 101$ & .96 \\
\hline Total protein $(\mathrm{g} / \mathrm{dL})$ & $6.9 \pm 0.4$ & $6.8 \pm 0.5$ & .6 \\
\hline \multicolumn{4}{|l|}{ Preoperative levels } \\
\hline Hemoglobin (g/dL) & $11.6 \pm 0.9$ & $13.0 \pm 1.1$ & $<.01$ \\
\hline Reticulocytes $(0 / 00)$ & $25 \pm 11$ & $13 \pm 5$ & $<.01$ \\
\hline Platelets $\left(10^{3} / \mu \mathrm{L}\right)$ & $302 \pm 70$ & $303 \pm 66$ & .98 \\
\hline Total protein $(\mathrm{g} / \mathrm{dL})$ & $6.7 \pm 0.4$ & $7.3 \pm 0.4$ & $<.01$ \\
\hline
\end{tabular}

Data are given as mean $\pm \mathrm{SD}$ where indicated. $A S D$, Atrial septal defect; $V S D$, ventricular septal defect; others, double-chambered right ventricle $(\mathrm{n}=1)$, left ventricular-right atrial communication $(\mathrm{n}=1)$, and aortic valvular stenosis.

*One month before the operation in the control group.

small children by analyzing the surgical results of patients weighing less than $20 \mathrm{~kg}$.

\section{Methods}

From December 1992 to March 1999, 134 children aged 0 to 16 years underwent cardiac operations for simple anomalies in our institution. Almost all of them were regarded as PAD candidates, and the first donation was planned approximately 1 month before surgery. Among these candidates, 37 patients weighing under $20 \mathrm{~kg}$ accepted PAD. The range of weight was 13 to $20 \mathrm{~kg}(19 \pm 2 \mathrm{~kg})$, and that of age was 3 to 9 years ( $6 \pm 1$ years). Their anomalies were atrial septal defect $(n=22)$, ventricular septal defect $(n=12)$, double-chambered right ventricle $(n=1)$, left ventricular-right atrial communication $(\mathrm{n}=1)$, and aortic valvular stenosis $(n=1)$. Within the preceding weight and age ranges, there were 25 patients who were excluded from the PAD protocol during the same period. Their weights and ages ranged from 13 to $19 \mathrm{~kg}(18 \pm 2 \mathrm{~kg})$ and 4 to 8 years $(6 \pm 2$ years), respectively. The anomalies were atrial septal defect $(n=15)$ and ventricular septal defect $(n$ $=10$ ). The reasons for exclusion were poor cooperation and refusal for fear, locomotive problems, and religious forbiddance. These patients served as control subjects.

Informed consent was obtained from patients and family members during the initial visit. The PAD procedure was clearly explained to ensure complete understanding and compliance by the patient during blood donation. About 1 month before the operation, the patient and family visited the blood transfusion unit. Throughout blood donation, the staff and family, usually the mother, encouraged or relaxed the patient by various methods. Only local anesthetic agent was applied to the puncture site, usually the upper limb. After confirming that the hemoglobin level was greater than $11 \mathrm{~g} / \mathrm{dL}$, the patient's blood was withdrawn and processed into packed red cells, fresh frozen plasma, and whole blood. The preserving solution was mannitol-adenine-phosphate solution, which allows up to 6 weeks' storage. Five to $10 \mathrm{~mL} / \mathrm{kg}$ autologous blood was obtained at every donation, which was performed by simple withdrawal and storage or the leapfrog method. ${ }^{16}$ We usually selected the simple method for the patient with a PAD period of less than 4 weeks and the leapfrog method for the patient with a longer PAD period. In the latter, withdrawal of blood was followed by reinfusion and withdrawal of additional blood at 1 - to 2-week intervals, yielding fresh whole blood, packed red cells, and fresh frozen plasma. We scheduled the final storage volume of the autologous blood to be approximately $40 \mathrm{~mL} / \mathrm{kg}$.

For conservation of the patient's blood, blood was salvaged by conventional ultrafiltration and cell processing during the operation, and residual blood in the CPB circuit was returned to the patient within the operative day. The other procedures for blood conservation, such as acute normovolemic hemodilution, pharmacologic measures, and postoperative autotransfusion of shed mediastinal blood were not performed. Criteria for blood transfusion included anemia with a hematocrit level of less than $15 \%$ during $\mathrm{CPB}$ and a hemoglobin level of less than $8 \mathrm{~g} / \mathrm{dL}$ after CPB or circulatory disturbance with mixed venous oxygen saturation of less than $60 \%$ despite adequate cardiac output, as estimated by clinical impression or echocardiography. In addition, whole autologous blood, except fresh frozen plasma, was reinfused within the first postoperative day. 
Table II. Surgical factors

\begin{tabular}{|c|c|c|c|}
\hline Variables & PAD patients $(n=37)$ & Control subjects $(n=25)$ & $\mathrm{P}$ value \\
\hline \multicolumn{4}{|l|}{ Procedure } \\
\hline ASD closure (direct/patch) & $22(20 / 2)$ & $15(15 / 0)$ & \\
\hline VSD closure (direct/patch) & $12(10 / 2)$ & $10(10 / 0)$ & .7 \\
\hline Others & 3 & 0 & \\
\hline Operation time (min) & $191 \pm 32$ & $200 \pm 27$ & .2 \\
\hline Perfusion time (min) & $49 \pm 26$ & $46 \pm 17$ & .6 \\
\hline \multicolumn{4}{|l|}{ Priming volume of CPB } \\
\hline Absolute (mL) & $1164 \pm 160$ & $1214 \pm 183$ & .3 \\
\hline Relative (mL/kg) & $64 \pm 9$ & $66 \pm 9$ & .2 \\
\hline Minimum hematocrit (\%) & $18 \pm 2$ & $18 \pm 5$ & .14 \\
\hline
\end{tabular}

Data are given as mean \pm SD where indicated. ASD, Atrial septal defect; VSD, ventricular septal defect; direct, direct closure; patch, patch closure; others, intracardiac repair for double-chambered right ventricle $(n=1)$, left ventricular-right atrial communication $(n=1)$, and open commissurotomy for congenital aortic stenosis.

Surgery consisted of primary intracardiac repair of a simple anomaly. The CPB circuit was primed with asanguineous solution. After systemic heparinization, mild-to-moderate hypothermic CPB was used with a hollow-fiber membrane oxygenator. Myocardial protection was achieved by means of cold blood cardioplegia, and topical myocardial cooling was achieved by means of cold saline solution. Before discontinuation of $\mathrm{CPB}$, all patients were warmed to a rectal temperature of $36^{\circ} \mathrm{C}$ or more. The heparin effect was neutralized by protamine sulfate until the activated coagulation time had normalized.

Patient profile and PAD-related and operative factors were studied. Complications related to autologous blood donation, preservation, and reinfusion were surveyed throughout the course. Exposure to homologous blood, excess autologous blood, perioperative changes, and hemoglobin, reticulocyte, platelet, and serum protein levels were examined.

Data are expressed as mean \pm SD. Continuous variables, such as fluid and blood volume, are generally expressed as relative values to body weight. All statistical analyses were conducted by JMP Statistical Discovery Software (SAS Institute, Inc, Cary, NC). Differences in the mean and rate were determined by the Student $t$ test and the $\chi^{2}$ test. Changes in the consecutive data were compared between the groups by analysis of variance.

\section{Results}

Patient profiles, including age, weight, sex, and diagnosis, did not differ significantly between PAD patients and control subjects. Hemoglobin, reticulocyte, platelet, and total protein levels were also similar between the groups at the beginning. However, hemoglobin and total protein levels immediately before the operation were significantly lower in the PAD group than in the control group. On the contrary, the reticulocyte level was significantly higher in the PAD group (Table I).

PAD was initiated $50 \pm 16$ days (range, 20-72 days) before the operation and was performed $6 \pm 2$ times.
The total volume of stored autologous blood was $48 \pm$ $17 \mathrm{~mL} / \mathrm{kg}$ per patient. According to component, autologous whole blood was $35 \pm 15 \mathrm{~mL} / \mathrm{kg}$, packed red cells were $22 \pm 6 \mathrm{~mL} / \mathrm{kg}$, and fresh frozen plasma was $25 \pm 26 \mathrm{~mL} / \mathrm{kg}$. During PAD, hemoglobin and total protein levels decreased by $1.1 \pm 1.1 \mathrm{~g} / \mathrm{dL}$ and $0.4 \pm 0.4$ $\mathrm{g} / \mathrm{dL}$ after PAD, respectively.

Two patients experienced a vasovagal reflex consisting of faintness, nausea, and paleness, which was caused by transient hypotension and bradycardia during blood donation. They quickly recovered without any further complications. Rethoracotomy was not required in any of the patients, and no other complications, such as infection, thrombosis, or embolism, were observed in the patients.

Surgical factors, including procedure, operation time, perfusion time, priming volume, and the minimum hematocrit level during CPB, did not differ significantly between the groups (Table II). There was a negative correlation between body weight and relative priming volume (PAD group: $P<.01, r^{2}=0.2$; control group: $\left.P=.2, r^{2}=0.08\right)$, as well as between the minimum hematocrit level and relative priming volume (PAD group: $P<.01, r^{2}=0.4$; control group: $P=.5, r^{2}=0.03$ ).

Blood loss did not significantly differ between the 2 groups. During the operation, blood loss was $7 \pm 1$ $\mathrm{mL} / \mathrm{kg}$ in PAD patients and $6 \pm 1 \mathrm{~mL} / \mathrm{kg}$ in control subjects $(P=.3)$. Chest tube drainage during 24 hours after the operation was $11 \pm 4 \mathrm{~mL} / \mathrm{kg}$ in PAD patients and 10 $\pm 3 \mathrm{~mL} / \mathrm{kg}$ in control subjects $(P=.2)$.

Homologous blood was not transfused to any of the PAD patients (0/37 [0\%]), and $43 \pm 13 \mathrm{~mL} / \mathrm{kg}$ autologous blood was used overall. All of the donated whole blood or packed red cells were transfused; however, some of the fresh frozen plasma was not reinfused (14/37 [38\%] patients), amounting to $11 \pm 6 \mathrm{~mL} / \mathrm{kg}$ per patient. In contrast, $20(80 \%)$ of 25 control patients 

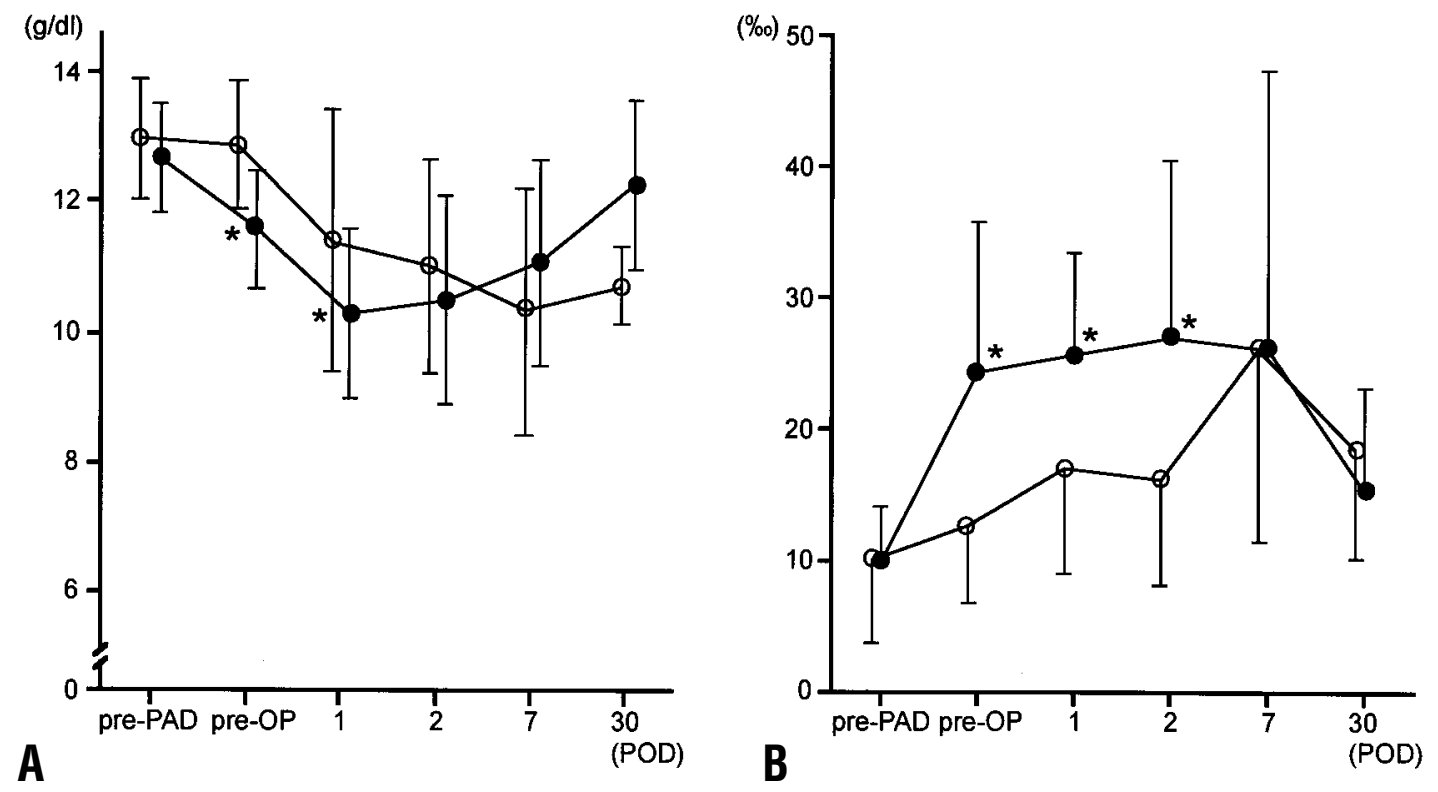

Fig 1. Perioperative changes in hemoglobin (A) and reticulocyte (B) levels. Closed circles and open circles represent the PAD and control groups, respectively. $O P$, Operation; $P O D$, postoperative day. Data are given as mean \pm SD. ${ }^{*} P<.05$, PAD group versus control group.

were exposed to homologous blood $(P<.01$, PAD patients vs control subjects). The mean transfused volume was $29 \pm 22 \mathrm{~mL} / \mathrm{kg}(P<.01$, PAD patients vs control subjects).

The perioperative changes in hemoglobin level were examined between the 2 groups. Just before the operation, the hemoglobin level was significantly lower in the PAD group than in the control group. As mentioned above, the hemoglobin level decreased by $1.1 \pm 1.1$ $\mathrm{g} / \mathrm{dL}$ in the PAD group, and the corresponding figure was $0.1 \pm 0.4 \mathrm{~g} / \mathrm{dL}$ in the control group $(P<.01)$. Bleeding ceased quickly, and chest drains were removed within the first postoperative day. Blood transfusion was discontinued until the second postoperative day in all of the patients. The hemoglobin level reached a nadir on the first postoperative day and then increased in the PAD group. That of the control group decreased monotonously until the seventh postoperative day (Fig $1, A)$. Change of hemoglobin level from the second to the seventh postoperative day was significantly larger in the PAD group than in the control group $(0.6 \pm 1.3$ $\mathrm{g} / \mathrm{dL}$ vs $-1.1 \pm 1.0 \mathrm{~g} / \mathrm{dL}$, respectively; $P<.01)$. From the preoperative day to the second postoperative day, the reticulocyte level of the PAD group was around 25 $0 / 00$, which was significantly higher than that of the control group (Fig 1, B). However, a significant difference was not found thereafter between the groups.
Changes in platelet counts did not differ significantly between the PAD and control groups throughout the course of treatment (Fig 2, A). Mean values decreased below $200 \times 10^{3} / \mu \mathrm{L}$ on the first and second postoperative days and recovered to preoperative levels by the seventh postoperative day. The total protein level was significantly lower in the PAD group than in the control group immediately before the operation (Fig 2,B). It reached the lowest level on the first postoperative day and changed very little thereafter in either group throughout the course of treatment.

\section{Comment}

Children tend to be susceptible to infection and immune disorders because their immune system has not yet completely matured. ${ }^{10}$ Consequently, complications caused by homologous blood transfusion can be more severe in children than in adults. Carriers of human T-lymphotropic virus type 1 (HTLV-1) constitute approximately $15 \%$ of the population in the southern Japanese island of Kyushu. This rate is remarkably higher than corresponding values in nonendemic areas (0.02\%-0.04\%) ${ }^{1-3}$ Screening for antibodies to HTLV-1 is routinely performed here. However, seroconversion to HTLV-1 may occur even after screening donor blood. ${ }^{1,2}$ Manifestation of HTLV-1-associated myelopathy after cardiac surgery has also been reported in 

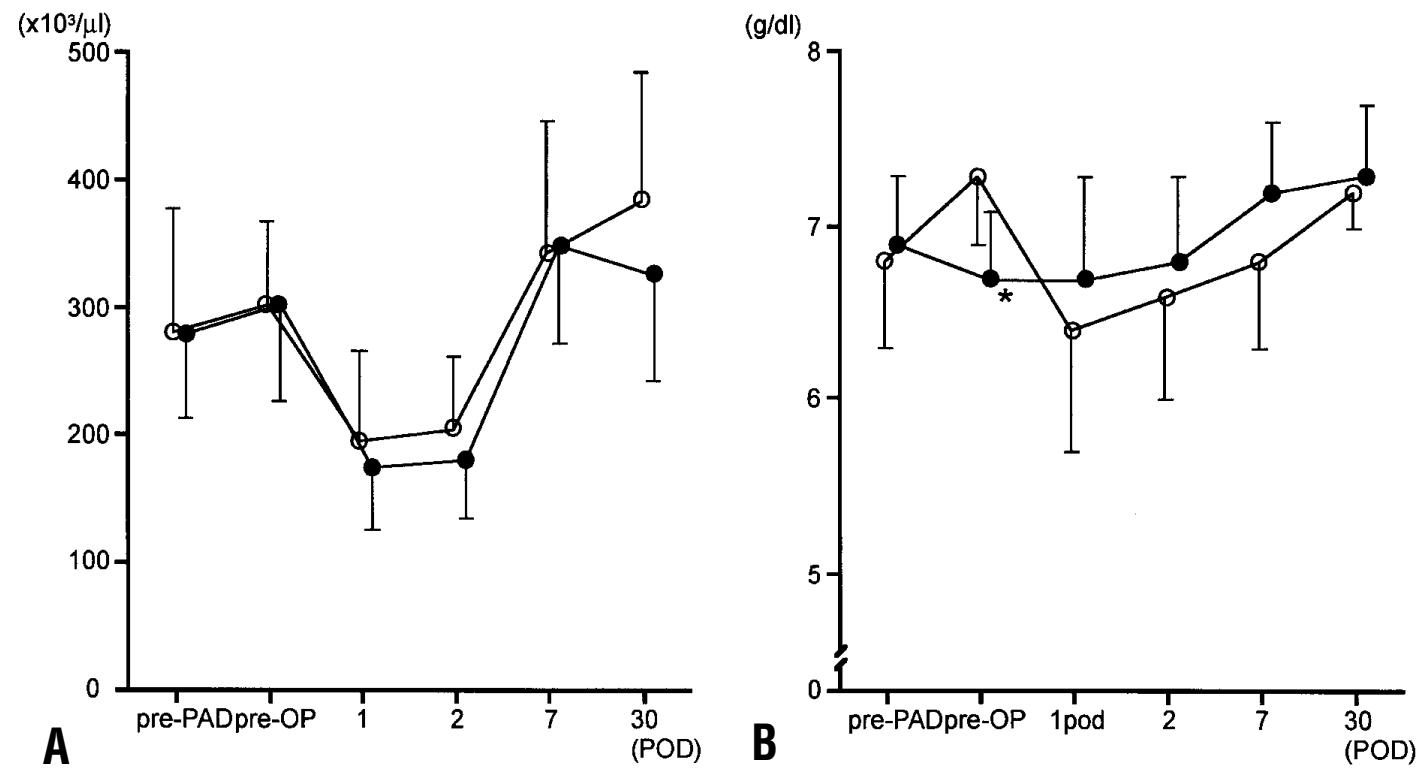

Fig 2. Perioperative changes in platelet (A) and total protein $(\mathbf{B})$ levels. Closed circles represent PAD patients, and open circles represent control subjects. $O P$, Operation; $P O D$, postoperative day. Data are given as mean \pm SD. ${ }^{*} P<.05$, PAD patients versus control subjects.

such patients. ${ }^{4}$ Similar findings have also been reported in human HIV-1, hepatitis B virus, and hepatitis C virus. $^{1-3,5,6}$ In addition, because life expectancy is long in children, the lifetime risk of overt infection, liver cirrhosis, or neoplasm caused by viral transmission will be comparatively higher. Therefore, exposure to homologous blood should be avoided as much as possible in children. ${ }^{10}$

To avoid homologous blood transfusion in cardiac operations performed in children-in other words, to conserve the patients' own blood-several methods have been studied clinically. They include PAD by liquid or frozen storage, acute normovolemic hemodilution, reduced priming volume of $\mathrm{CPB}$, blood salvage by filtration or cell processing, modified ultrafiltration, autotransfusion of shed mediastinal blood, and pharmacologic means. ${ }^{9,10,12-18}$

There are not many articles about PAD for children in the current era. Masuda and colleagues ${ }^{11}$ conducted PAD for 80 patients with a mean weight of $29 \mathrm{~kg}$ (range, $12-69 \mathrm{~kg}$ ). They donated $735 \pm 388 \mathrm{~mL}$ of autologous blood and avoided allogenic transfusion in $94 \%$ of patients. Although they conclude that PAD is a safe and effective method, there are some authors who claim it is a bothersome and outdated technique. ${ }^{8}$ Most of the blood conservation procedures attempt to reduce hemodilution caused by CPB. The present results exhibit a negative correlation between relative priming volume and hematocrit level, indicating that decreasing hemodilution is a reasonable and effective approach in children..$^{9,10,12,13}$ On the other hand, autotransfusion of shed mediastinal blood remains controversial because of the risk of bacterial contamination or activation of the systemic inflammatory response. ${ }^{9,10}$ Pharmacologic means are applied to facilitate erythropoiesis, improve coagulation, or inhibit fibrinolysis, resulting in favorable outcomes. ${ }^{9}, 10,15,17$

Almost all measures except PAD are usually conducted during or immediately after surgery, a busy and vulnerable period. On the other hand, PAD is performed before surgery and thus does not affect surgical time. PAD is also the only method that increases the absolute volume of the patient's own blood. In the present study there were no serious complications related to PAD, and none of these patients required homologous blood. In addition, postoperative recovery of the hemoglobin level was significantly better in the PAD group and was accompanied by a higher reticulocyte level. This suggests flourishing erythropoiesis ascribed to PAD. These results indicate the clinical efficacy of PAD in prevention of homologous blood transfusion in children.

Despite these positive findings, PAD has not seen widespread acceptance in cardiac operations in children. ${ }^{9-11}$ Recent improvements in CPB, resulting in a remarkable decrease in the priming volume, likely 
explain this lack of acceptance of PAD. Other factors include family stress, the lengthy donation period, the labor intensiveness of the procedure, and concerns about worsening the primary cardiac lesion. However, PAD can be coupled with other methods to reduce the storage volume, which may be a direct and effective means of resolving these problems. As an alternative, blood collection during cardiac catheterization, pharmacologic activation of erythropoiesis, improved preservation solutions, and simplification of the procedures may also be of benefit. In the present study the absolute priming volume of our CPB system was initially 1000 to $1200 \mathrm{~mL}$. This has since been reduced to 600 to $800 \mathrm{~mL}$. As to the influence of this reduction of priming volume, we found a significant decrease in allogenic blood exposure in the control group (15/16 patients with priming volumes of $>800 \mathrm{~mL}$ and $5 / 9$ patients with priming volumes from $600-800 \mathrm{~mL} ; P=$ $.04)$. In the PAD group we could not find a significant difference in the minimum hematocrit level during CPB $(17 \% \pm 2 \%$ in patients of priming volume of > $800 \mathrm{~mL}$ vs $18 \% \pm 3 \%$ in patients of priming volume from $600-800 \mathrm{~mL} ; P=.8$ ). In addition, we changed the preservation solution from a citrate-phosphate-dextrose solution to a mannitol-adenine-phosphate solution, which elongates the preservation period from 3 to 6 weeks. Through these alterations, none of our patients now requires the leapfrog method for blood donation, thus improving the efficacy of PAD. ${ }^{11}$ Given the unique effects offered by PAD, this method continues to be an important option of blood conservation in cardiac operations in children.

On the basis of the present study, we conclude that PAD can be performed safely and can be clinically effective, even in children under $20 \mathrm{~kg}$. This technique can be further improved through coupling with different procedures for blood conservation.

\section{REFERENCES}

1. Shih JWK, Lee HH, Falchek M, et al. Transfusion-transmitted HTLV-I/II infection in patients undergoing open-heart surgery. Blood 1990;75:546-9.

2. Cohen ND, Munoz A, Reitz BA, et al. Transmission of retroviruses by transfusion of screened blood in patients undergoing cardiac surgery. N Engl J Med 1989;320:1172-6.

3. Dodd R. The risk of transfusion transmitted infection. N Engl J Med 1992;327:419-21.

4. Akita T, Hayase S, Yano Y, et al. Two cases of HTLV-I associated myelopathy (HAM) after cardiac operation. J Jpn Assoc Thorac Surg 1990;91:1808-11.

5. Klein HG. Allogeneic transfusion risks in the surgical patient. Am J Surg 1995;170(Suppl 6A):21S-6S.

6. Cooley DA. Conservation of blood during cardiovascular surgery. Am J Surg 1995;170(Suppl 6A):53S-9S.
7. Sandrelli L, Pardini A, Lorusso R, Sala ML, Licenziati M, Alfieri O. Impact of autologous blood predonation on a comprehensive blood conservation program. Ann Thorac Surg 1995;59:730-5.

8. Salem MR, Mastrianno L, Joseph NJ. Preoperative autologous blood donation. In: Salem MR, editor. Blood conservation in the surgical patient. Baltimore: Williams \& Wilkins; 1996. p. 146-67.

9. Mohr R, Goor DA, Lavee J. Nonpharmacological and topical means. In: Mohr R, Goor DA, Lavee J, editors. Management of bleeding after open heart surgery. Austin: R.G. Landes Company; 1997. p. 131-76.

10. Helm RE, Krieger KH. Intraoperative autologous blood donation practices. In: Krieger $\mathrm{KH}$, Isom OW, editors. Blood conservation in cardiac surgery. New York: Springer-Verlag; 1998. p. 281-325.

11. Masuda M, Kawachi Y, Inaba S, et al. Preoperative autologous blood donations in pediatric cardiac surgery. Ann Thorac Surg 1995;60:1694-7.

12. Matsuki O, Matsuda H, Shimazaki Y, et al. Open heart surgery without homologous blood transfusion in small children of body weight less than $20 \mathrm{~kg}$. J Jpn Assoc Thorac Surg 1992;40:235-41.

13. Takahashi Y, Tatsuno K, Kikuchi T. Open heart surgery with bloodless priming for cyanotic congenital heart diseases-the role of autologous blood donation after induction of anesthesia. $\mathrm{J}$ Jpn Assoc Thorac Surg 1996;44:1075-81.

14. Draaisma AM, Hazekamp MG, Frank M, et al. Modified ultrafiltration after cardiopulmonary bypass in pediatric cardiac surgery. Ann Thorac Surg 1997;64:521-5.

15. Fukahara K, Murakami A, Ueda T, et al. Scheduled autologous blood donation at the time of cardiac catheterization in infants and children. J Thorac Cardiovasc Surg 1997;114:505-7.

16. Utley JR, Moores WY, Stephens DB. Blood conservation techniques. Ann Thorac Surg 1981;31:482-90.

17. Horiba K, Itoh Y, Terada H, et al. Experience of predeposit autologous blood transfusion and medication of recombinant human erythropoietin in pediatric open heart surgery. Kyobu Geka 1991;44:1146-50.

18. Kurisu K, Yonenaga K, Miyamoto K, et al. Open heart surgery without the use of homologous blood in infants and young children: effectiveness of the intraoperative autologous blood donation from arterial monitoring line. Kyobu Geka 1999;52:438-41. 